\title{
DINÁMICA DE LA ESTRATIFICACIÓN SOCIAL EN ALGUNAS CIUDADES PEQUEÑAS Y MEDIANAS DE MÉXICO
}

\author{
José luis Reyna, Manuel Villa y Kirsten Albrechtsen * \\ El Colegio de México
}

\section{INTRODUCCIÓN}

El presente trabajo es una nueva etapa de la investigación que bajo el título de "La clase media mercantil en las ciudades pequeñas y medianas de México" ha venido desarrollando el Centro de Estudios Económicos y Demográficos de El Colegio de México. ${ }^{1}$ Hasta ahora, dicha investigación ha producido dos trabajos; el primero de ellos, de Claudio Stern, ${ }^{2}$ es un intento de sistematización teórica y empírica del concepto de región y su principal contribución es una tipología de regiones basada en algunos criterios de desarrollo económico. El segundo, de Ricardo Cinta, ${ }^{3}$ destaca algunos de los aspectos fundamentales del proceso de urbanización de cien ciudades pequeñas y medianas.

Estos dos estudios han servido para desarrollar el presente, pero a diferencia de ellos -en los que se han estudiado procesos más generales (el desarrollo económico y la urbanización, en regiones y municipios, respectivamente) - en el actual la estrategia de investigación se ha orientado hacia el análisis de un fenómeno más específico: el de la dinámica de la estratificación social en algunas ciudades pequeñas y medianas del país.

Una primera hipótesis de trabajo es que los cambios ocurridos a nivel global en la estructura de clases durante el presente siglo se han reflejado también en las ciudades de tamaño "intermedio". La justificación de esta hipótesis es que al presentarse la situación de cualquier cambio a nivel nacional puede quedar oculto lo que acontece en sectores específicos de la estructura. Un cambio determinado puede

* Los autores agradecen la colaboración de Raúl de la Peña en cuanto a la programación y cómputo de las correlaciones presentadas en la sección 6 , así como los comentarios y críticas de diversos investigadores del Centro de Estudios Económicos y Demográficos.

1 Investigación propuesta por el Dr. Rodolfo Stavenhagen.

2 Claudio Stern, Las regiones de México y sus niveles de desarrollo socioeconómico. Tesis profesional. México, Unniversidad Nacional Autónoma de México, Escuela Nacional de Ciencias Políticas y Sociales, 1966. (Véase también su artículo, "Un análisis regional de México", Demografía Y Economía, I, 1, 1967.)

3 Ricardo Cinta, Aspectos socioeconómicos de la urbanización en México. Tesis profesional. México, Universidad Nacional Autónoma de México, Escuela Nacional de Ciencias Políticas y Sociales, 1967. 
ser atribuido al desarrollo de algunos centros o regiones, en tanto que el resto de la estructura puede permanecer relativamente estable; pero esto no implica que a nivel global no se haya experimentado tal cambio. Así, por ejemplo, la industrialización se explica por el desarrollo de algunas zonas (el valle de México y algunos estados del norte) en tanto que otras no han experimentado un crecimiento industrial significativo (como acontece con los estados del sur). No obstante, se dice que el país como estructura global se está industrializando.

Una segunda hipótesis sostiene que entre los cambios ocurridos en la estructura de clases de las ciudades pequeñas y medianas destaca la rápida formación de una "clase media" ${ }^{4}$ que se encuentra en íntima relación con las actividades terciarias y que a su vez depende de las agrícolas.

Ahora bien, al contrario de lo que sostiene la literatura convencional -que la Revolución de 1910 ha sido el factor "causal" de la mayoría de los cambios ocurridos en la estructura global mexicana- en este trabajo se sustentará la tesis de que la Revolución Mexicana fue un factor entre otros que originó tales cambios y que entre los demás factores se encuentran algunos que son parte de un proceso histórico particular de desarrollo. Este proceso, dentro de un límite, es común a los países que actualmente se encuentran en vías de desarrollo, especialmente los que constituyen el área latinoamericana. Dentro de este proceso destaca el proceso de "terciarización", algunos de cuyos rasgos sobresalientes se señalarán más adelante.

\section{EL CONTEXTO DE ANÁLISIS: LAS CIUDADES PEQUEÑAS Y MEDIANAS}

Como uno de los objetivos del actual trabajo es continuar la investigación iniciada y sistematizar algunos conceptos y la información empírica acumulada, se decidió tomar como unidades de análisis las mismas cien ciudades que estudió Cinta; el que sus definiciones y conceptos sean discutibles no impide la tarea de sistematización. Según dicho autor, en 1960, único año que analiza, hubo 100 municipios y 106 localidades consideradas como ciudades pequeñas y medianas. Fueron seleccionadas con base en dos criterios: 1) se fijó un límite de población entre 5000 y 50000 habitantes, considerando el primero más adecuado para distinguir lo "rural" de lo "urbano" que el criterio censal (2 500 habitantes) y el segundo como un tope para englobar a las ciudades pequeñas y medianas; y 2) que fueran urbanas, seleccionando aquellas en que el $65 \%$ de la población habitara en localidades de 5000 habitantes y más. Las 100 ciudades se distribuyeron en 25 estados y en 6 clases de desarrollo de acuerdo con la tipología de regiones elaborada por Stern. ${ }^{5}$

4 En este trabajo no se utilizarán de manera rigurosa los conceptos de estrato, clase, estructura de clases y estratificación social; como es sabido, son muy difíciles de definir. Véanse intentos al respecto en $\mathrm{S}$. Ossowski, Class Structure in the Social Consciousness, Nueva York, The Free Press, 1963; R. Stavenhagen, "Estratificación social y estructura de clases", Ciencias Politicas y Sociales, México, enero-marzo de 1962, Núm. 27, pp. 73-103.

5 Claudio Stern, op. cit., Cap. III; y "Un análisis regional de México", pp. 92-117. 
Cabe señalar que aun cuando a lo largo de este trabajo se usará el término "ciudad", las unidades de análisis son en realidad municipios. Se carece de datos a nivel de localidades en el censo de 1960, por lo que es necesario trabajar a nivel municipal, usando el término ciudad sólo como convención particular. ${ }^{6}$

Se toma como punto de referencia el año de 1960, efectuándose un análisis retrospectivo de las ciudades que existían ya en 1940 y en 1900 . La selección de estos años tiene dos justificaciones: 1) corresponden a tres puntos históricos de trascendental importancia en México, pues 1900 representa el apogeo de la época porfiriana en sus aspectos económicos, políticos y administrativos; en 1940 la reforma agraria se encontraba en uno de sus momentos más dinámicos y se iniciaba a su vez la actual etapa de industrialización del país; y 1960, refleja, en buena medida, la situación actual ; y 2) la información que más se ajustaba a los requerimientos de este trabajo, referida a la posición en la ocupación por rama de actividad económica, se encontró en los censos de esos años.

La mayoría de las ciudades existía ya antes de la Revolución y casi en su totalidad para 1940 . En 1900 , se encontraron 69 , en tanto que para 1940 el total ascendía a 94. De las 100 ciudades, 43 en 1900 y 82 en 1940 se encontraban dentro del intervalo de población de 5000 a 50000 habitantes.

De las cifras del cuadro 1 sobresalen los siguientes puntos: 1) en 1900 y 1940 había ya una importante proporción de ciudades (43/69 y $82 / 94$, respectivamente) con población entre 5000 y 50000 habitantes; 2) en los tres años considerados la media de población es muy superior al límite censal urbano (2500) e incluso al límite adoptado en este trabajo $(5000)$; 3) las ciudades analizadas, aun en 1900, asumían ya las características de pequeñas y medianas, al menos desde è punto de vista demográfico.

Como es sabido, los análisis de estratificación ${ }^{7}$ se fundan en la clasificación de la posición del individuo de acuerdo con uno o varios criterios medibles objetivamente -ingreso, educación, ocupación, etcétera-, clasificación que viene a constituir por lo tanto una variable ordinal. Tal análisis, a diferencia del estudio marxista de las clases sociales, no atiende en forma exclusiva a la posición del individuo con respecto a los medios de producción. En este trabajo el análisis de la estratificación se basa en el indicador ocupación, tanto por la confiabilidad que encierra ${ }^{8}$ como por ser el que cuenta con mayor

6 Cinta, op. cit., Cap. II.

7 La literatura sobre estratificación es en extremo abundante. Entre los trabajos más significativos, véanse J. Kahl, The American Class Structure, Nueva York, Rinehart and Winston, 1957; R. Centers, The Psychology of Social Classes, Princeton University Press, 1949; Ll. Warner, et al., Social Classes in America, Nueva York, Harper and Row, 1960; y el libro de R. Bendix y S. M. Lipset (compiladores), Class, Status and Power, Nueva York, The Free Press, 1966, Ossowski (op. cit., Cap. 10) diferencia los estudios de estratificación de los de clases sociales.

8 La ocupación es un indicador que muestra alta correlación con otros indicadores de status socioeconómico, tales como la educación, el ingreso, etc., y además es el indicador que mejor explica otras variables. Con referencia a Estados Unidos, véase J. Kahl y J. Davies, "A Comparison of Indexes of Socio-Economic Status", American Sociological Review, Núm. 20, 1955; sobre Brasil y México, en perspectiva 


\section{Cuadro 1}

México: Características pRincipales de algunas ciudades peoueñas Y MEDIANAS EN COMPARACIÓN CON LA POBLACTÓN TOTAL, 1900-1960

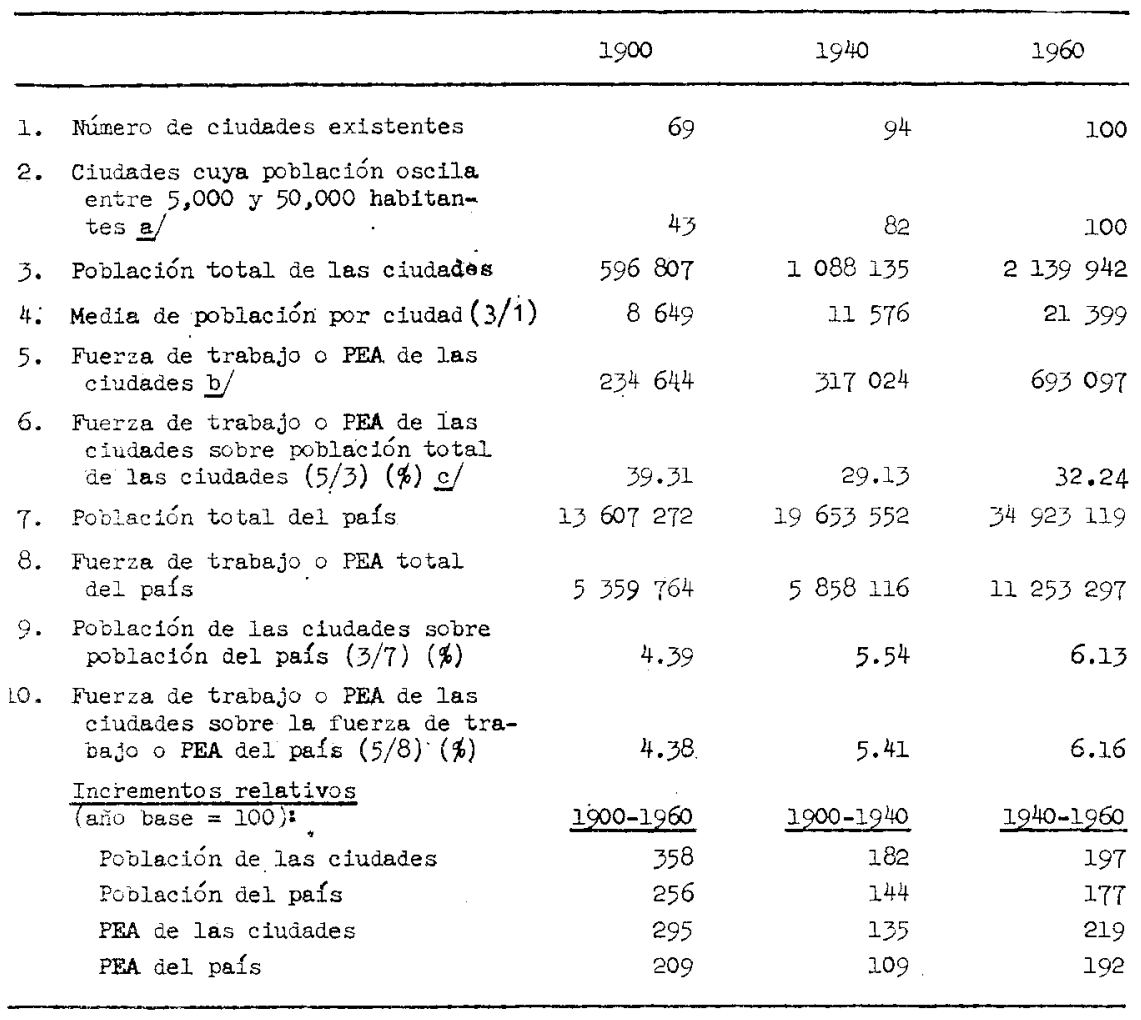

Fuentes: Ministerio de Fomento, Dirección General de Estadística, Censo General de Población de 1900, bajo la dirección del Dr. Antonio Peñafiel (verificado el 8 de octubre de 1900), México, 1905; Secretaría de la Economía Nacional, Dirección General de Estadística, VI Censo General de Población, México, 1943; Secretaría de Industria y Comercio, Dirección General de Estadística, VIII Censo General de Población, México, 1963.

a En el análisis se tomaron todas las ciudades existentes en cada uno de los años.

b El concepto de fuerza de trabajo aparece en 1900 y 1940 y el de población cconómicamente activa en 1960.

c Los totales de donde se obtuvieron los porcientos se encuentran en el mismo cuadro: 
información censal. No obstante, conviene aclarar que en lo que toca a los censos mexicanos, se encuentran limitaciones que impiden obtener un mayor provecho de su utilización.

La metodología seguida para efectuar las comparaciones censales de las ocupaciones se describe en el Apéndice (véanse las pp. 393-394).

3. La estructura de clases en el MéXico prerrevolucionario y SU FISONOMÍA ACTUAL

La estructura de clases que prevaleció en México desde la época de la colonia hasta principios de este siglo se aproximaba al tipo dicotómico, es decir, la coexistencia de dos estratos superpuestos. ${ }^{9}$ Según Othón de Mendizábal, a principios del siglo XIX los españoles peninsulares, constituidos en estrato dominante, 10 representaban sólo el $1.2 \%$ de la población. ${ }^{11} \mathrm{~A}$ fines de siglo tal situación no había experimentado modificaciones sustanciales. Entre las pocas investigaciones sobre el tema, se encuentra que para 1895 la clase alta constituía el $1.44 \%$, y si bien la clase media ya alcanzaba el $7.78 \%$, la estructura conservaba su carácter rígido pues las clases bajas representaban el $90.78 \%$ del total, siendo su composición esencialmente de peones y jornaleros de campo.12 González Cosío estima que para 1900, aunque con ligeras variaciones, las clases altas representaban tan sólo el $0.6 \%$, mientras la clase baja constituía el $91.1 \% .13$

No obstante que en estas investigaciones existen diferencias en la obtención de los resultados, el hecho sobresaliente es que los autores concuerdan en que la clase alta era una minoría y que la llamada clase baja o popular representaba más de las nueve décimas partes del total. Esta situación descansaba en el sistema de propiedad basado

comparada, véase J. Kahl, The Measurement of Modernization: A Study of Values in Brazil and Mexico (de próxima publicación); sobre Brasil, véase G. A. Dillon Soares, "Los estratos sociales y las elecciones presidenciales de 1960 en Brasil", Revista Mexicana de Sociologia, xxIv, septiembre-diciembre, 1962, e "Interesse politico, conflicto de pressôes e indecição eleitoral nas eleições de 1960 no estado de Guanabara", Sintese Politica, Economica e Social, IX, marzo de 1961; y sobre Puerto Rico, M. Tumin, "Las clases sociales y el desarrollo en Puerto Rico", en J. Kahl (compilador), La industrialización de América Latina, México, Fondó de Cultura Económica, 1965.

9 Sobre la concepción histórica de la estructura de clase dicotómica, véase Ossowski, op. cit., especialmente el Cap. I.

10 Tal vez sea mejor hablar de castas que de estratos o clases. La justificación es que casta, como concepto sociológico, supone un agregado de individuos que no permiten el acceso hacia adentro y que no participan hacia afuera. Estratificación, mientras tanto, implica cierto número de estratos, así como cierto grado de movilidad.

11 "En la estratificación de las clases étnico-sociales, el español criollo constituía teóricamente el estrato superior o privilegiado; pero en la realidad, tanto en el orden público como en el económico, la supremacía de los españoles sobre los criollos fue acentuándose en el curso de los siglos." M. Othón de Mendizábal, "El origen histórico de nuestras clases medias", en Sociedad Mexicana de Difusión Cultural, Las clases sociales en México, Colección Tlapali, s.f., p. 6.

12 José Iturriaga, La estructura social y cultural de México. México, Fondo de Cultura Económica, 1951, p. 28.

13. A. González Cosío, "Clases y estratos sociales", en J. Kahl, La industrialización en América Latina, pp. 241-261. 
en la hacienda y en el carácter predominantemente rural de la economía mexicana.

Aun cuando durante el régimen de Díaz se había iniciado una nueva era de "reconstrucción" con la realización de obras como ferrocarriles, el establecimiento de industrias manufactureras y la instalación de energía eléctrica, estas modificaciones no alteraron significativamente la estructura de clases y el funcionamiento de la economía, que siguió siendo predominantemente rural. ${ }^{14}$

La Revolución Mexicana fue un factor que coadyuvó a quebrantar y modificar el orden de cosas prevaleciente, y esas transformaciones se hicieron más acusadas a partir de los últimos tres decenios. Si bien subsiste un amplio sector agrícola (en 1960, el $53 \%$ de la población económicamente activa se dedicaba a las actividades primarias y el $49 \%$ de la población total era rural), los cambios habidos en la estructura de clase apuntan hacia una sociedad de clases relativamente más abierta. Según González Cosío, en 1960 la clase alta permaneció, con respecto a 1900 , casi invariable $(0.7 \%)$, en tanto que la clase media se duplicó durante el período señalado de 8.3 a $17.1 \%$, dando como resultado menor proporción de clases populares, de lo que se puede concluir que la sociedad mexicana ha experimentado una tasa de movilidad social de alguna significación a la vez que la casi absoluta rigidez que la caracterizaba ha disminuido en algún grado.1.

\section{DINÁMICa de La ESTRATIFICACIÓN SOCIAL EN LAS CIUdAdES PEOUEÑAS Y MEDIANAS}

Los cambios en la estructura de clases de la sociedad mexicana durante el presente siglo han sido a nivel global y no parcial; es decir, no son sectores aislados los que han cambiado para dar una nueva fisonomía a la estructura, sino que tales cambios, aun cuando no se hayan efectuado de manera homogénea, han abarcado la totalidad. Para 1900, las ciudades pequeñas y medianas presentaban una estructura de clases muy aproximada al modelo dicotómico, y reflejaban una situación semejante a la que prevalecía a nivel nacional. El estrato alto (compuesto principalmente por propietarios, profesionistas y técnicos) representaba tan sólo el $1.52 \%$, mientras que los estratos más bajos constituían el $91.72 \%$. (Véase el cuadro 2.)

Los estratos medios, si bien más numerosos que el estrato alto, representaban también en 1900 una baja proporción con respecto al total; a principios de siglo, la estructura de clases de las ciudades pequeñas $\mathrm{y}$ medianas era sumamente rígida.

14 F. Brandenburg, The Making of Modern Mexico, Englewood Cliffs, N. J., Prentice Hall, 3a ed., 1965, pp. 108-155; L. Solís, "Hacia un análisis general a largo plazo del desarrollo económico de México", Demografía y Economía, I, 1, 1967.

15 A. González Cosío, op. cit. También puede verse el trabajo de $\mathrm{H}$. Cline, Mexico, Revolution to' Evolution, 1940-1960, Londres, Oxford University Press, 1962. Este autor estima que para 1956 las clases altas representaban el $0.7 \%$ y la clase media el $27.2 \%$. Si bien esta cifra puede estar sobrestimada, sus datos también sugieren la existencia de una tasa de movilidad de alguna significación. La literatura disponible sobre los estudios de estratificación social en México se resume en Claudio Stern, The Changing Stratification Profile: a Preliminary Survey (inédito). 
Cuadro 2

México: Cambios en la estratificación social en algunas ciudades PEQUEÑAS Y MEDIANAS, 1900-1960

(En porcientos)

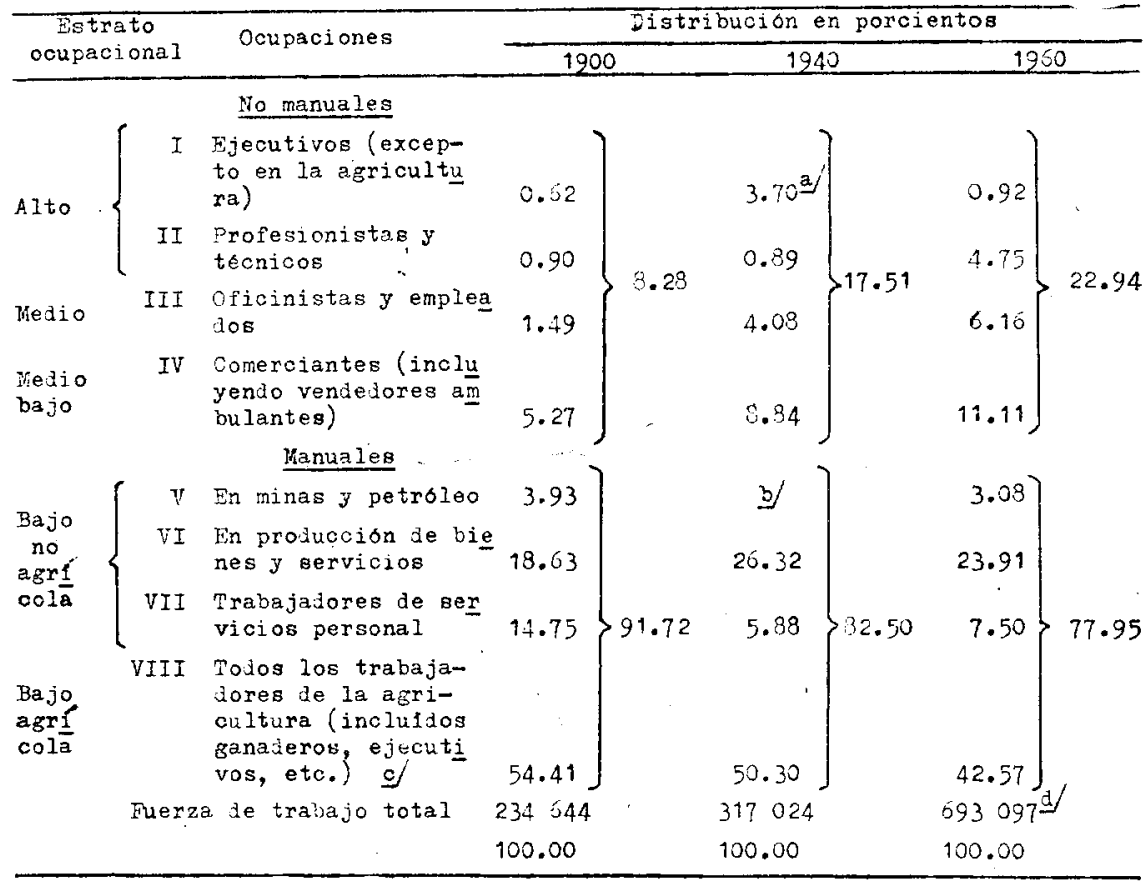

a Este porciento se encuentra "sobrecargado" debido a que en el censo de 1940 gran parte de los individuos que tenían una pequeña empresa aparecen como administradores.

b El censo de 1940 registra los datos de minería agregados a los de la industria, no siendo posible descomponerlos, por lo cual se carece del dato.

c En el censo de 1940 no aparece especificada la ocupación de propietario de tierras; al no poder hacerse una diferenciación de las ocupaciones que aparecen reportadas en el censo entre estratos altos y bajos, y al constituir éstos más del $90 \%$ del total, todas las ocupaciones, incluidas las no bajas, han quedado dentro de esta categoría.

d En 1960, población económicamente activa (véase el cuadro 1).

Nota: Para tratar de justificar la clasificación ocupacional elaborada, sobre todo en la ordenación que se presenta, se ha efectuado el cálculo (a nivel nacional por carecer de datos municipales) del ingreso mensual per capita de cada uno de los estratos ocupacionales presentados. Los resultados fueron los siguientes (el número romano indica el estrato ocupacional): I) 4364 , II) 3345 , III) 957, IV) 716 , V) 696 , VI) 595, VII) 375 y VIII) 360 . Nótese la tendencia descendente del ingreso cuando baja el estrato ocupacional, lo que sugiere una alta correlación entre ambas variables. Esto da un grado de confiabilidad razonable a la clasificación acupacional presentada. El procedimiento para calcular estos datos, y con el fin de controlar la "dispersión intra-estrato", fue el de usar el promedio en pesos en cada intervalo de ingreso. Los datos utilizados provienen de un estudio, con base en una muestra, efectuado por la Secretaría de Industria y Comercio, La población económicamente activa de México, México, Dirección General de Muestreo, 1965. Tomo VII, cuadros 8 y 9 , pp. 34 y 37. 
Las transformaciones que se observan en 1940 son muy marcadas, en comparación con 1900. Por un lado, el estrato alto, según la clasificación utilizada, aumentó considerablemente y llegó a constituir el $4.59 \% .^{16}$ Los estratos bajos son bastante numerosos todavía, pero los estratos medios casi se duplican en esos 40 años, en detrimento de las actividades agrícolas y manuales en general. (Véase el cuadro 2.)

La tendencia se mantiene hasta 1960 , con aumento más o menos señalado del estrato alto y expansión más significativa de los estratos medios, ambos fenómenos en detrimento de la población ubicada en los rangos más bajos de la escala social.

El cuadro 3 muestra con mayor amplitud la naturaleza de dichos cambios entre 1900 y 1960 , en particular las transformaciones ocurridas en la estructura de clases. Como puede verse, los estratos no manuales se han incrementado, en tanto que los manuales han disminuido, sobre todo el que se encuentra involucrado en las actividades agrícolas. Es de notar que el estrato bajo no agrícola, compuesto en lo principal de artesanos, obreros (industriales, de minas y petróleo), experimenta un decremento relativamente bajo, lo que sugiere que el mayor desplazamiento se localiza del sector agrícola al de los servicios.

Estos cambios indican, por un lado, que el sistema de estratificación de las ciudades pequeñas y medianas tiende más a uno de tipo

\section{Cuadro 3}

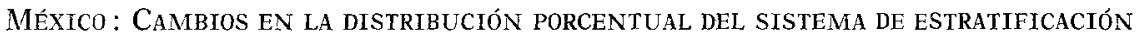
DE ALGUNAS CIUDADES PEQUEÑAS Y MEDTANAS, 1900-1960

(En porcientos)

\begin{tabular}{|c|c|c|c|c|c|c|}
\hline & \multicolumn{3}{|c|}{ Ocupaciones no manuale: } & \multicolumn{3}{|c|}{ Ocupaciones manuales } \\
\hline & $\begin{array}{c}\text { Estiato } \\
\text { alto } \\
\text { (I, II) } \\
\text { a }\end{array}$ & $\begin{array}{c}\text { Estrato } \\
\text { medio } \\
\text { (III) }\end{array}$ & $\begin{array}{l}\text { Estrato } \\
\text { nedio- } \\
\text { bajo } \\
\text { (IV) }\end{array}$ & $\begin{array}{l}\text { Estrato } \\
\text { bajo no } \\
\text { agrico- } \\
\text { Ia } \\
\text { (V, VI, } \\
\text { VII) }\end{array}$ & $\begin{array}{l}\text { Estrato } \\
\text { bajo a- } \\
\text { grícola } \\
\text { (VIII) }\end{array}$ & Dotal \\
\hline 3900 & 1.52 & I. 49 & 5.27 & 37.31 & 54.41 & 100.0 \\
\hline $\begin{array}{c}1960 \\
\text { Campio en la }\end{array}$ & 5.67 & 6.16 & 11.11 & 34.49 & 42.57 & 100.0 \\
\hline porcentual & 4.15 & 4.67 & 5.84 & -2.82 & -11.84 & \\
\hline
\end{tabular}

Fuente: cuadro 2.

a Los números romanos indican estratos ocupacionales.

16 En el censo de 1940, el estrato de "ejecutivos" incluye propietarios y administradores de muy pequeñas empresas (comerciales, artesanales, etc.). Éste es el motivo principal por el que se incrementa tanto el porciento. No obstante, el incremento de la clase alta en los 60 años conserva una tendencia ascendente, lo que posiblemente indica algún grado de comparabilidad. 
moderno, al decrecer las actividades manuales y ensancharse las no manuales. Por otro, la intensidad diferencial de esos cambios sugiere que hay movilidad social de los rangos bajos hacia otros más elevados, pero que unos estratos se incrementan más rápidamente que otros.

Dentro de los estratos que más han crecido se encuentran aquellos que se relacionan directamente con las actividades comerciales $(5.84 \%)$; el crecimiento del estrato correspondiente a oficinistas y empleados posiblemente se pueda explicar debido al gran aumento de las actividades relacionadas con la burocracia, tanto pública como privada; en tanto que el incremento del estrato alto puede deberse, entre otros factores, en grado importante a las reformas educativas, que dan acceso mayor al sistema educacional. Este es también un factor explicativo del incremento de los estratos medios.

Sin embargo, los cambios cuantitativos en el sistema de estratificación no reflejan los cambios cualitativos que, de hecho, han ocurrido en el presente siglo. A principios de siglo, el estrato alto, compuesto por profesionistas, técnicos y propietarios, alcanzaba en comparación con 1960 (definidos de la misma manera) un rango relativamente superior. Esto se debía, entre otras razones, a la falta de movilidad que hacía más restringido el acceso a él. Pero no sucede ya en 1960, cuando existe mayor movilidad que permite a personas de los estratos medios y aun de los bajos incorporarse a los más elevados.

Los estratos medios, mientras tanto, pueden nutrirse desde dos direcciones distintas: ${ }^{17}$ desde arriba y desde abajo. Una de las consecuencias del movimiento revolucionario fue la abolición de una clase terrateniente dominante que, al perder su status en el antiguo orden, ingresó a las filas de los estratos medios. Los estratos más bajos dispusieron de mayores oportunidades de movilidad social, debido a los cambios que aceleró la Revolución, pasando también a ensanchar los estratos medios. Entre los muchos factores que explican la tendencia de crecimiento de estos últimos se pueden destacar la creciente comercialización, la industrialización más o menos sostenida del país y las reformas educativas. ${ }^{18}$

Estos mismos factores dan cuenta de la tendencia descendente de la proporción de estratos bajos, en especial los agrícolas. La reforma agraria originó una nueva categoría social: el pequeño propietario rural y el ejidatario; el primero puede considerarse como clase media, mientras que el segundo constituye más bien un estrato "transicional" que no se puede considerar de los rangos más bajos en el mismo sentido que se consideraba al peón y al jornalero a principios de siglo.

Dentro de esta problemática, algunos autores señalan que si bien los estratos más bajos han disminuido en términos relativos, en cifras absolutas se han proliferado con gran rapidez durante el transcurso del presente siglo. ${ }^{19}$ Esto se explicaría por la tasa de incremento de la población, que probablemente es mayor que la tasa de movilidad social. En otras palabras, aun habiendo un incremento de las oportu-

17 Esta hipótesis ha sido propuesta por N. Whetten, "El surgimiento de una clase media en México", en Sociedad Mexicana de Difusión Cultural, op. cit., p. 54.

18 Ibid., p. 57.

10 Pablo González Casanova, La democracia en México, México, Era, 1965, Cap. V. 
nidades de ascenso dentro de la escala social, la población que tiene acceso a dichas oportunidades es menor. No obstante, es innegable la tendencia que se observa y que apunta a que el sistema de estratificación en las ciudades pequeñas y medianas se encamine hacia uno más "moderno", al alejarse progresivamente del modelo dicotómico $\mathrm{y}$ existir algún grado de movilidad social.

5. CARACTERÍSTICAS SOCIOLÓGICAS DEL PROCESO DE DESARROLLO Y LA ESTRUCTURA de Clases EN Las CIUdAdES PEQUeÑas Y MEdianas de MÉxtco

En la literatura sociológica sobre los cambios en la estructura de clases de México, se establece como punto cronológico de referencia el año de 1910, momento en que se inicia la Revolución Mexicana. Si bien la Revolución transformó radicalmente la estructura económica, política y social del país, puede afirmarse que algunos de los procesos que se consideraban resultantes de ella se encontraban ya "incubados" antes del movimiento armado.20

Rasgos sobresalientes. Sin entrar en una discusión detallada del tema, ${ }^{21}$ se parte del hecho de que el desarrollo $\mathrm{y}$ su supuesto correlato, el subdesarrollo, son fenómenos históricos. Los países hoy desarrollados comenzaron su crecimiento sostenido desde la Revolución Industrial, mientras que los países ahora subdesarrollados fueron en su mayoría colonizados, estableciéndose en ellos una economía dependiente del exterior basada en la producción primaria y en el comercio. En los países hoy desarrollados se quebrantó la estructura feudal; y se generó una diferenciación del sistema productivo con amplia división del trabajo; por lo tanto, hubo cambios en la estructura ocupazional, con rompimiento del rígido sistema de estratificación representado por la relación siervo-señor. ${ }^{22} \mathrm{Si}$ bien al principio el desarrollo le la industria generó gran número de obreros manuales que, según oredicción de Marx, llevaría a una polarización de la estructura de zlases, la evidencia histórica ha permitido comprobar que tal desırrollo industrial provocó paralelamente la especialización que, aunada al adelanto teconlógico, dio lugar al surgimiento de una nueva categoía social de trascendental importancia en la estructura de clases: el le las clases medias.

20 Una tesis semejante en el caso francés fue sostenida por A. de Tocqueille; véase The old Régine and the French Revolution, Nueva York, Doublelay, 1955.

21 Pueden consultarse los siguientes trabajos que tratan este tema: J. Medina Zchavarría, Consideraciones sociológicas sobre el desarrollo económico, Buenos tires, Solar-Hachette, 1963; F. H. Cardoso, El proceso de desarrollo en América atina, Santiago de Chile, ILPES, 1965; C. Furtado, Subdesarrollo y estancamieno en América Latina, Buenos Aires, EUDEBA, 1966; Desarrollo y subdesarrollo, 3uenos Aires, EUDEBA, 1964; Formación económica del Brasil, México, FCE, 1962;

O. Sunkel, El marco histórico del proceso de desarrollo y subdesarrollo, Saniago de Chile, ILPES, 1966.

22 Véase el Cap. 2: "The Influence of Technological Changes on the Developrent of Class Structure in Western Europe", en G. D. H. Cole, Studies in Class tructure, Londres, Routledge and Kegan Paul, 1961. 
Habiéndose experimentado el desarrollo industrial, y por lo tanto el económico, los actuales países desarrollados acusan un crecimiento proporcionalmente menor de la fuerza de trabajo industrial, explicado en gran parte por la mecanización y un aumento de las actividades terciarias, ${ }^{23}$ que tiende a hacer predominar los estratos medios en la estructura de clases. En los países en vías de desarrollo, las características de este proceso son distintas. La tecnología no es creada sino importada, la agricultura sigue teniendo un peso fundamental en la estructura económica, el sector terciario crece con gran rapidez y el proceso de industrialización, si bien no inexistente pero sí incipiente, no alcanza todavía un nivel que estimule, de manera fundamentaí, el desarrollo económico. ${ }^{24}$

Una generalización que se puede extraer es la siguiente: el sector industrial absorbe poca mano de obra en tanto el sector de "servicios" experimenta un crecimiento de gran intensidad a costa de una disminución de la población activa en el sector primario.

DDada la estructura económica de los países latinoamericanos, se puede argumentar que un aumento de la producción agropecuaria, sin un proceso de industrialización importante, ha originado una amplia comercialización del producto agrícola y a su vez desarrollado las actividades directamente relacionadas con el comercio. ${ }^{25}$

De esta manera, se puede decir que una de las características del "nuevo proceso" de desarrollo es la presencia de un sector terciario "sobrecargado" que desequilibra la estructura ocupacional al no corres. ponderle al sector industrial un rango equivalente. México, al ser un país que pertenece a la categoría del "nuevo desarrollo", presenta esa situación, ${ }^{26}$ que puede ser ilustrada con algunos datos: en 1940, el

23 Ibid.

24 Véase un análisis empírico de estas dimensiones en siete países latinoamericanos, en F. H. Cardoso y J. L. Reyna, "Industrialization, Occupational Structure and Social Stratification", en Cole Blasier (compilador), Constructive Change in Latin America, Pittsburgh, Center for Latin American Studies (de próxima publicación). Véase también el trabajo de G. A. Dillon Soares, The New Industrialization and the Brazilian Political System, Santiago de Chile, FLACSO, 1966.

25 Misra, un historiador hindú, descubre la misma relación en Inglaterra en el siglo XIv. Véase The Indian Midale Classes: their Growth in Modern Times, Oxford University Press, 1961.

26 Si se compara el caso de México con el de otros países latinoamericanos y algunos desarrollados, se observa con gran nitidez "la hipertrofia del terciario" en el nuevo "proceso de desarrollo":

\begin{tabular}{lcccc}
\hline & & \multicolumn{3}{c}{ Sectores (\%) } \\
\cline { 3 - 5 } & & Primario & Secundario & Terciario \\
\hline México & 1960 & 53 & 17 & 30 \\
Argentina & 1960 & 22 & 21 & 57 \\
Brasil & 1960 & 52 & 13 & 35 \\
Inglaterra & 1951 & 5 & 49 & 46 \\
Estados Unidos & 1950 & 13 & 37 & 50 \\
\hline
\end{tabular}

Fuente: Simposio Interamericano de Industrialización, El proceso de industrializa. ción en América Latina, anexo estadístico, Santiago de Chile, CEPAL, 1966, p. 11. 
sector de los servicios (transportes, comercio, gobierno) contribuía con el $45.8 \%$ del producto bruto interno, en contraste con el $31.0 \%$ de la producción industrial (manufacturas, minería, petróleo, construcción). Para 1962, las participaciones fueron de 48.9 y $33.9 \%$, respectivamente. En el mismo período $1940-1962$ el producto por persona en el sector servicios se elevó $52.5 \%$, en tanto que en el sector industrial el incremento fue de $30.5 \%$. A su vez, el producto del sector servicios fue en 1962 de 74.4 millones de pesos (a precios de 1960), en tanto que el industrial era de 51.7 millones.

La terciarización en las ciudades pequeñas y medianas $[$ El proceso de desarrollo que se verifica en las ciudades pequeñas y medianas, si bien distinto al de los centros urbanos mayores al tener aquéllas una relación más estrecha con la agricultura, ${ }^{28}$ tal vez presente algunas características semejantes a las que ocurren en la estructura global cuando se toma ésta en su conjunto. Las hipótesis en que se apoyan estas afirmaciones sugieren que las ciudades pequeñas y medianas presentan una alta proporción de población económicamente activa en la agricultura, la que disminuye progresivamente a favor del sector servicios, y, a una tasa relativamente menor, del sector industrial. A su vez, el proceso de "terciarización", característica común de los países en vías de desarrollo, tenderá a generar, más que ningún otro sector de actividad económica, una capa relativamente amplia de estratos medios?

Bajo el supuesto de que la Revolución no hubiese tenido lugar, tal vez México se asemejaría a otros países latinoamericanos: una disminución progresiva del latifundio aun cuando sin llegar a su total exterminación; un proceso de industrialización basado fundamentalmente en el fenómeno denominado de la "sustitución de importaciones"; y como la industria no absorbe gran cantidad de mano de obra, ${ }^{29}$ un sector terciario con tendencia a crecer en mayor medida. Además, la concentración del ingreso contribuye sustancialmente a mantener esa situación.

Una de las consecuencias de la Revolución, para el caso mexicano, es el impulso que ha dado al desarrollo industrial, 30 pero el ritmo de crecimiento de este sector de actividades sigue estando por debajo del que experimenta el sector de los servicios.

Con objeto de dar algún apeyo empírico a las hipótesis formuladas, se ha construido el cuadro 4. Como puede observarse, la tendencia de descenso relativo de la ocupación en actividades agrícolas es más o

27 Solís, op. cit., cuadros 14 y 15 .

28 En 1960, el $42 \%$ de la PEA se dedicaba a la agricultura en tanto que sólo el $2.3 \%$ de la PEA en actividades agrícolas correspondía al Distrito Federal.

29 Por ejemplo, entre 1950 y 1960 tan solo se generaron 434000 nuevas ocupa. ciones industriales en el Brasil. C. Furtado, Dialéctica del desarrollo, México, FCE, 1965, p. 19.

30 En el período 1930-1960, el producto generado por persona en el sector manufacturero de México casi se cuadruplicó: las cifras fueron de $\$ 34.4$ (dólares de 1960) el primer año, en tanto que en 1960 alcanzó $\$ 112.1$; lo que coloca a México en el tercer lugar de los países latinoamericanos en lo que se refiere al producto generado por la industria. Simposio Latinoamericano de Industrialización, op. cit., p. 23. 
menos marcada. En el caso de las ciudades pequeñas y medianas su decremento durante los 60 años analizados es de $11 \%$. Aun cuando la población económicamente activa crece en números absolutos, las proporciones indican que el pasaje más importante que se experimenta es del sector agrícola al de los servicios. Mientras que el industrial gana tan sólo el $3 \%$ durante el período considerado, el sector de los servicios logra el $8 \%$. En el conjunto de la República la tendencia es semejante: una disminución relativa de las actividades agrícolas, a cambio de un incremento relativo de las terciariass]

\section{Cuadro 4}

MÉxico: Estructura ocupacional de LAS cIUdAdES PEQUEÑas Y MEdIANAS Y DE LA REPÚBLICA, 1900-1960

(En porcientos del total)

\begin{tabular}{|c|c|c|c|c|c|c|}
\hline \multirow[t]{2}{*}{ Sector } & \multicolumn{3}{|c|}{$\begin{array}{l}\text { Ciudades pequeñas } \\
\text { y medianas a }\end{array}$} & \multicolumn{3}{|c|}{ República Mexicana b/ } \\
\hline & 1900 & 1940 & 1960 & 1900 & 1940 & 1960 \\
\hline Agrícola & 54 & 50 & 43 & 70 & 67 & 53 \\
\hline Industrial & 22 & 24 & 25 & 21 & 13 & 17 \\
\hline Servicios & 24 & 26 & 32 & 9 & 20 & 30 \\
\hline $\begin{array}{l}\text { Fuerza de trabajo } \\
\text { total (en miles) }\end{array}$ & 234 & 317 & 693 & 4512 & 5694 & 11873 \\
\hline
\end{tabular}

a Censos de población 1900, 1940 y 1960.

b Simposio Latinoamericano de Industrialización. El proceso de industrialización en América Latina, Anexo estadístico, CEPAL, Santiago de Chile, 1966. Cuadro I-13, p. 13.

e Los totales de la República Mexicana difieren de los presentados en el cuadro 1 por tratarse de fuentes distintas.

Se advierte también que en 1900 fue relativamente elevada la proporción de la población dedicada a la industria. En las ciudades pequeñas y medianas llegaba a constituir el $22 \%$, en tanto que en el país era de $21 \%$. Destaca el hecho de que en la República en su conjunto, la participación relativa de la ocupación industrial se redujo fuertemente, de $21 \%$ a $17 \%$, entre 1940 y 1960.

Las hipótesis explicativas de esos fenómenos pueden ser las siguientes. En 1900, la "industria" era predominantemente artesanal. Es posible que ese tipo de industria prevalezca todavía hoy en las ciudades pequeñas y medianas, lo que no implica que las industrias modernas no tengan cabida en esas localidades. Mientras tanto, en el conjunto nacional la industria podía también considerarse como artesanal a principios de siglo; sin embargo, en los años subsiguientes, y especialmente a partir de los años cuarenta, su carácter ha 
cambiado de una industria de tipo artesanal a una predominantemente fabril, ,1 $^{31}$ en que juegan un papel destacado la ciudad de México y sus alrededores.

Pero a pesar del crecimiento sostenido de la industria y el cambio cualitativo de su composición, la "terciarización" es uno de los procesos que más acusadamente se presenta en el proceso de desarrollo, reflejado con alguna fidelidad en la estructura ocupacional. El sector terciario de las ciudades pequeñas y medianas acusa un crecimiento más o menos significativo, al igual que sucede en el país, con la diferencia de que en éste el ritmo de crecimiento es más acentuario. Sin embargo, ya para 1900 era importante, en términos cuantitativos, el sector de servicios en contraste con el mismo sector en el país, que era solamente del $9 \% .^{32}$ De esta manera, la estructura ocupacional en las ciudades pequeñas y medianas, aun a principio de este siglo, denotaba ya una tendencia a un aumento más acelerado del sector terciario en comparación con la industria.

En el país en su conjunto, parecería que tal fenómeno ocurre después del movimiento armado, lo que sugiere la hipótesis, a ser desarrollada con posterioridad, de que en las ciudades pequeñas y medianas las actividades comerciales tenían ya un grado relativamente alto de importancia hace 60 años.

De lo anterior puede desprenderse una conclusión provisional: Ua "terciarización" afecta tanto a la estructura ocupacional del país en su conjunto como a la de las ciudades pequeñas y medianas, lo que indica que el proceso de desarrollo de México es distinto al experimentado por los países de desarrollo original.

Terciarización y estructura de clases. Pasando ahora a la hipótesis de que la "terciarización" tiende a generar una capa relativamente amplia de estratos medios, a diferencia de los otros sectores de actividad económica (la agricultura y la industria), y de que dicho proceso es una característica distintiva del actual proceso de desarrollo en comparación con el verificado en los países hoy industrializados, se han encontrado los resultados que se muestran en el cuadro 5. Aunque la confiabilidad de los datos es limitada, indican situaciones que se aproximan a las que se han supuesto en este trabajo.

El sistema de estratificación del sector primario, así como del secundario, era nítidamente de tipo dicotómico. La inexistencia de estratos medios da claro panorama de la rigidez de la estructura que prevalecía a principios de siglo. Observando los cambios ocurridos a partir de entonces, se han obtenido las siguientes pautas de movilidad.

En tanto que la participación relativa del estrato alto del sector agrícola disminuye, el mismo estrato, dentro del sector industrial, experimenta un relativo ascenso.

31 En tanto que para 1925 el $70 \%$ de la población ocupada en el sector manufacturero se clasificaba como artesanal, para 1960 esta proporción disminuyó al $35 \%$. Ioid., pp. 17-18.

32 Las ciudades pequeñas y medianas que se estudian se encontraban ya, incluso a principio de este siglo, arriba del límite elegido para considerar a una localidad como pequeña o mediana. Véase el cuadro 1 , donde se indica que la media de población en 1900 era de 8649 habitantes. 


\section{Cuadro 5}

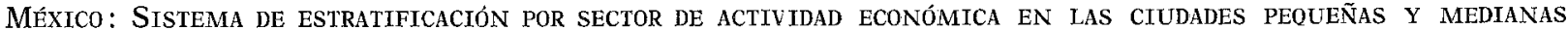
EN 1900 Y 1960, y EN LA REPÚBLICA EN 1956

(En porcientos del total)

\begin{tabular}{|c|c|c|c|c|c|c|c|c|c|c|}
\hline \multirow{3}{*}{ Ocupaciones } & \multirow{3}{*}{ Estratos } & \multicolumn{6}{|c|}{ Ciudades pequeñas y medianas } & \multirow{3}{*}{$\frac{\text { República }}{\text { Primario }}$} & \multicolumn{2}{|c|}{ Mexicana, $1956 \mathrm{~b}$} \\
\hline & & \multicolumn{2}{|c|}{ Primario } & \multicolumn{2}{|c|}{ Secundario } & \multicolumn{2}{|c|}{ Terciario } & & \multicolumn{2}{|c|}{ Secun- Terciario } \\
\hline & & 1900 & 3960 & 1900 & 1960 & 1900 & 1960 & & dario & \\
\hline \multirow{2}{*}{ Mo manuales } & Alto & 1.12 & 0.39 & 0.28 & 4.86 & 6.23 & 13.81 & 0.2 & 0.1 & 1.0 \\
\hline & Medio & 0.00 & 1.45 & 0.00 & 7.26 & 27.50 & 42.94 & 20.3 & 8.0 & 60.0 \\
\hline Yaruales & Bajo & 98.88 & 98.16 & 99.72 & 88.88 & 66.27 & 38.25 & 89.5 & 91.8 & 39.0 \\
\hline \multicolumn{11}{|c|}{ Euerza de trabajo (en mi- } \\
\hline
\end{tabular}

a Censos de 1900 y 1960.

b Claudio Stern, The Changing Stratification Profile: a Preliminary Survey (inédito); los datos son de A. González y han sido reordenados por el primero.

Nota sobre definiciones:

Tomando como referencia la clasificación ocupacional aparecida, en el Censo de 1960 (véase el Apéndice Metodológico en este trabajo), las definiciones han sido hechas en la siguiente forma:

Estrato alto: estratos ocupacionales I y II (profesionistas, técnicos y ejecutivos)

Estrato medio: estratos ocupacionales III y IV (empleados, dependientes y comerciantes)

Estrato bajo: estratos ocupacionales V a VIII (obreros, trabajadores de servicio personal y población dedicada a ocupaciones agrícolas)

Las definiciones presentadas son de tipo operacional; desde un punto de vista teórico pueden ser criticables, pues de hecho son muy limitadas; no obstante, era la única alternativa para aproximarse al análisis de la dinámica de la estratificación social por medio de cifras censales. La ordenación de los estratos en alto, medio y bajo descansa, además de en la jerarquización de ocupa* ciones, en el cómputo del ingreso mensual per capita por estrato ocupacional, que aparece en el cuadro 2. 
El estrato medio, inexistente en ambos sectores a principios de siglo, aparece después del movimiento armado, teniendo mayor importancia en el sector industrial que en el agrícola.

Con respecto al estrato bajo, si bien los cambios cuantitativos que se perciben son insignificantes, sobre todo en el sector primario, la composición de esa clase es desde el ángulo cualitativo diametralmente distinta a la que prevalecía antes. En la actualidad, la clase baja agrícola se constituye de ejidatarios y minifundistas, mientras que antes se componía de peones y jornaleros. Los primeros -nuevo estrato social del campo- pueden considerarse como estrato transicional que cumple funciones de pequeño empresario - en el sentido de que toma decisiones-, lo que da sentido y significado distintos a la estructura de clases. No obstante, si se compara el rango relativo del ejidatario con los ocupados en otras actividades en el sector de actividad agrícola - tales como el pequeño propietario y los propietarios de pequeñas artesanías y comercios- se encuentra que el de aquél es todavía bajo.

El mismo caso puede considerarse en el sector industrial, donde la clase baja estaba compuesta principalmente de artesanos; ahora esas posiciones son ocupadas por obreros fabriles.

Con respecto al sector terciario, se puede decir que era y es el único sector de actividad que genera, en proporción significativa, estratos no bajos. Se puede apreciar en 1900 una proporción considerable de estratos altos y medios en comparación con los otros sectores, estratos que se han incrementado rápidamente en los 60 años analizados. Se puede concluir que los estratos medios existentes en 1900 eran generados por el sector terciario, que es también el que más contribuye a su formación en 1960, tal como lo indican las cifras correspondientes, incluyendo las del país en su conjunto.

De los mismos datos se desprende la observación de que el proceso de "terciarización" de las ciudades pequeñas y medianas es semejante al experimentado a nivel nacional. Esta característica se explica por la tesis que se ha intentado sostener a lo largo de este trabajo, esto es, que el proceso de desarrollo de los países no industrializados tiene características distintas al seguido en los países de desarrollo original.

Estos hallazgos encontrados a nivel de las ciudades pequeñas y medianas ofrecen apoyo a la hipótesis propuesta desde dos puntos de vista: a) el sector terciario tiene un peso fundamental, en términos de estratificación, en el nuevo proceso de desarrollo, al generar nuevas categorías sociales, fenómeno que tiene lugar antes de efectuarse la industrialización, y $b$ ) la generación de nuevas categorías sociales mediante el proceso de "terciarización" no ha sido producida por el movimiento armado sino que éste fue un factor que lo dinamizó - su germen se encontraba ya en el período anterior a la Revolución, tal como lo indican las cifras de 1900.

TEs significativo que, en dicho año, el sector terciario se componía en una tercera parte, con respecto a su total, de estratos medios y altos, proporción que casi se duplicó en el período 1900-1960, al alcanzar el $60 \%$.

Sin embargo, este fenómeno, que en el transcurso del trabajo se ha denominado de "terciarización", no es el único que genera nuevas 
categorías sociales, específicamente las clases medias. La reforma agraria y el proceso de industrialización han contribuido también a la formación de estratos medios, pero vale insistir en que es el sector terciario el que guarda la más estrecha correlación con ellos.

\section{Factores explicativos DE LOS EStratos Medios EN 1960}

Para intentar conocer algunos de los factores que tienen más impacto en la modificación del sistema de estratificación, se han seleccionado 12 variables, que se han puesto en relación con un índice simple de estratificación: la razón entre la población económicamente activa no manual y la manual, ${ }^{33}$ que será considerada como indicador de estratos medios.

La hipótesis de base es que esos factores o variables tendrán pesos diferenciales en la explicación de los estratos medios, es decir, que unos los explicarán más que otros; y que entre las variables analizadas, la proporción de población activa en ocupaciones terciarias será una de las que más enfáticamente "dará cuenta de" ese índice simple de estratificación. Se da especial atención a la relación entre el monto de la producción agropecuaria y los estratos medios, para intentar verificar la hipótesis de que las clases medias tienen íntima relación con las actividades agrícolas y que a mayor producción agropecuaria los estratos medios tenderán a ser mayores.

Las unidades de análisis son las 100 ciudades pequeñas y medianas que analizó Cinta. Considerando las 12 variables en relación con el índice de estratificación, se han encontrado los resultados que muestra el cuadro 6, del cual se puede concluir que las variables que explican en mayor grado el índice de estratificación son las que se relacionan con el proceso de "terciarización".

La existencia de estratos medios alcanza su máxima explicación en relación con la variable referente al porcentaje de población económicamente activa no agrícola. Esto se puede interpretar mediante la siguiente hipótesis: debido a que las ciudades pequeñas y medianas no experimentan un proceso de industrialización significativo, ${ }^{34}$ es el sector terciario en el que tiene que absorber los excedentes de población desplazada del primario.Como quedó asentado, el sector terciario genera una proporción elevada de estratos no bajos; esta variable también tiene alta correlación con estratos medios (.719). Por lo tanto, cuanto más elevada sea la proporción de la población econó-

33 Algunos trabajos han tomado este indice como indicador de estratos medios. Véase G. A. Dillon Soares, "Economic Development and the Class Structure", en Bendix y Lipset, op. cit., pp. 190-199; G. Germani, "Estrategia para estimular la movilidad social", en J. Kahl, La industrialización en América Latina, op. cit.; y F. H. Cardoso y J. L. Reyna, op. cit.

34 Entre 1940 y 1955 , el Valle de México aportó el $53.1 \%$ de la producción industrial, y las entidades del norte (Baja California Norte y Sur, Sonora, Chihuahua, Coahuila, Nuevo León, Tamaulipas) aportaron el $23.4 \%$. Véase P. Lamartine Yates, El desarrollo regional de México, México, Banco de México, Depto. de Investigaciones Industriales, 1962. 
Cuadro 6

MÉXico: CORRElactones de algunas variables económicas Y SOCtales CON LA RAZÓN DE OCUPACIONES NO MANUALES A MANUALES EN 100 CIUDAdES PEQUEÑAS Y MEdianas, 1960

\begin{tabular}{|c|c|c|c|}
\hline Variables & $\begin{array}{l}\text { Coeficiente } \\
\text { de correla- } \\
\text { ción a. }\end{array}$ & $\begin{array}{l}\text { Nivel de } \\
\text { signifi- } \\
\text { cactón b/ }\end{array}$ & $\begin{array}{c}\text { \% de la varianza } \\
\text { explicada por } \\
\text { regresión li- } \\
\text { neal c/ }\end{array}$ \\
\hline $\begin{array}{l}\text { \% de la } \mathrm{PEA} \text { - no acrícola } \\
\text { \% de la PEA en el sector }\end{array}$ & .805 & .001 & $65 \%$ \\
\hline terciario & .719 & .001 & $52 \%$ \\
\hline $\begin{array}{l}\text { \% de alfabetos ( } 6 \text { años y } \\
\text { más) }\end{array}$ & .694 & .001 & $48 \%$ \\
\hline $\begin{array}{l}\text { Número de establecimientos } \\
\text { comerciales }\end{array}$ & .630 & .001 & $40 \%$ \\
\hline \% de la PEA asalariada & .537 & .001 & $29 \%$ \\
\hline $\begin{array}{l}\text { \% de la PEA en el sector } \\
\text { secundario }\end{array}$ & .455 & .001 & $21 \%$ \\
\hline Producción industrial & .426 & .001 & $18 \%$ \\
\hline $\begin{array}{l}\text { of de la PEA en industrias } \\
\text { de transformación }\end{array}$ & .361 & .001 & $13 \%$ \\
\hline $\begin{array}{l}\text { Número de establecimientos } \\
\text { de servicios }\end{array}$ & .330 & .02 & $11 \%$ \\
\hline $\begin{array}{l}\text { Producción agrícola } \\
\text { Número de establecimientos }\end{array}$ & .305 & .02 & $10 \%$ \\
\hline industriales & .270 & .02 & $7 \%$ \\
\hline Tamaño de población & .089 & n.s. & $=$ \\
\hline
\end{tabular}

a Coeficientes $r$ de Pearsons.

b Con 100 observaciones, una correlación de 1946 es necesaria para un nivel de significación del $5 \%$ (Guilford, Psychometric Methods, Nueva York, McGraw Hill, 1964).

c Esta columna se obtiene elevando al cuadrado el coeficiente de correlación. Para una justificación de lo anterior, véase W. Hays, Statistics for psychologists, Nueva York, Holt Rinehart Winston, p. 501.

d $\mathrm{PEA}=$ población económicamente activa.

Nota: Para comparar estos resultados a nivel internacional (específicamente América Latina), véase G. A. Diilon Soares, "Economic Development and the Class Structure", en R. Bendix y L. M. Lipset, Class, Status and Power, Nueva York, The Free Press, 1966, pp. 190-199. 
micamente activa dedicada a actividades no agrícolas, más crecerá el sector de los servicios.

El alfabetismo es otro de los factores que, además de mostrar alta correlación con las otras dos variables, , $^{36}$ tiene impacto significativo en el sistema de estratificación. Aunque tal vez habría sido más conveniente controlar la variable de años de escolaridad, la correlación encontrada indica que el acceso a la educación es un factor que tiene peso muy importante en la formación de los estratos medios.

En relación con una de las hipótesis básicas que guían esta investigación -que las actividades comerciales y los estratos medios se encuentran en íntima relación-, se encontró lo siguiente: la asociación obtenida entre el número de establecimientos comerciales y el índice de estratificación es bastante estrecha (.630), lo que da apoyo a tal conjetura, incluso si se compara con las relaciones correspondientes al número de establecimientos de servicios e industriales con el índice de estratificación (.330 y .270). Se puede deducir que estas variables no explican las modificaciones en el sistema de estratificación de las ciudades pequeñas y medianas con la misma amplitud que la primera variable mencionada.

La introducción del sistema de salarios, que sustituye en parte al de pagos en especie y que absorbe alguna parte de la población dedicada a ocupaciones independientes, parece ser un factor condicionante en la aparición de los estratos medios. Esto sugiere que dichas categorías sociales dependen, en cierta medida, de actividades burocráticas, tanto públicas como privadas. Las actividades comerciales juegan un papel importante al generar un estrato de empleados y dependientes, así como de administradores.

La industria, por incipiente que sea, explica en algún grado la aparición de los estratos medios. Los indicadores utilizados -la proporción de la población activa en el sector secundario, en industrias de transformación, y el monto de la producción industrial- así lo indican. Con base en las correlaciones obtenidas con esas variables, que explican un porciento relativamente bajo de la varianza del índice de estratificación, se puede decir que la industria no es una condición tan rigurosa, en comparación con las actividades relacionadas con el sector terciario, pues se ha encontrado en algunas ciudades que, aun estando éstas arriba del promedio en cuanto a ocupaciones industriales, presentan una proporción baja de estratos medios. Esto es, de 44 ciudades por encima de la media, 15 presentaban tasas inferiores al $10 \%$ en su índice de estratificación, en tanto que 13 de las 44 alcanzaban más del $30 \%$ en la razón constituida por las ocupaciones no manuales sobre las manuales. Es posible que la industria sea un factor que polarice la estratificación social en el sentido de que puede generar una capa relativamente amplia de estratos medios (como sucedió en los países desarrollados), como también un grupo de ocupaciones pertenecientes a los rangos más bajos (como parecen indicar los resultados obtenidos).

35 A nivel nacional se ha encontrado entre esas dos variables una correlación de .85. J. L. Reyna, Desarrollo económico, distribución del poder y participación política: el caso de México (inédito).

36 R. Cinta, op. cit., p. 204. 
La relación entre la producción agropecuaria y el índice de estratificación no parece ser explicativa en la formación de estratos medios, lo que se puede notar en el resultado de la correlación (.305). Sin embargo, dada la importancia de la hipótesis que va con esta asociación, se hizo un intento de exploración, tomando en cuenta las ciudades que tenían una producción agropecuaria superior a la media. Los resultados se muestran en el cuadro 7 . Como puede observarse, el coeficiente de correlación, en este caso, ocultó una fuerte relación entre esas dos variables. Siendo la producción agropecuaria alta, dentro del contexto analizado, la proporción de estratos medios tenderá a crecer. Esto daría cierto apoyo a la hipótesis de que, en efecto, los estratos medios están relacionados con las actividades agropecuarias. Por lo tanto, un aumento en la productividad agrícola es un factor que modifica sustancialmente la estructura de clases en esas localidades. En otras palabras, la comercialización del producto agrícola, proceso que vincula áreas urbanas con agrícolas y posiblemente rurales, supone que al aumentar el volumen de la producción se generan nuevas ocupaciones no agrícolas urbanas que en su mayoría corresponden a estratos no bajos.

\section{Cuadro 7}

México: Proporción de estratos medtos en 100 ciudades pequeÑas y Medianas EN FUNCIÓN DEL MONTO DE SU PRODUCCIÓN AGROPECUARIA, 1960

(En porcientos del total)

\begin{tabular}{lcc}
\hline $\begin{array}{l}\text { \% de no manuales } \\
\text { sobre manuales af }\end{array}$ & $\begin{array}{c}\text { Arriba de la media } \\
(\$ 10.888,000 \mathrm{y} \text { más })\end{array}$ & $\begin{array}{c}\text { Abajo de la media } \\
\text { (menos de } \$ 10.888,000)\end{array}$ \\
\hline$-10 \%$ & 4 & 23 \\
10.1 a 20\% & 8 & 32 \\
20.1 a 30\% & 12 & 28 \\
$+30 \%$ & 76 & 17 \\
Número de ciudades & 25 & 75 \\
\hline
\end{tabular}

a La media aritmética del índice de estratificación es de $23.1 \%$.

Por último, entre el tamaño de la localidad y el índice de estratificación utilizado hay ausencia de correlación. Sin embargo, el resultado es significativo, pues indica que si se cumple la condición de que haya un mínimo de características tales como una proporción relativamente alta de población activa en el sector terciario, alfabetismo, alta proporción de población activa no agrícola y establecimientos comerciales, no habrá muchas probabilidades de encontrar elevada proporción de estratos medios con independencia relativa del tamaño de la localidad. Además, puede haber ciudades pequeñas y medianas que aun teniendo un tamaño de población relativamente grande, acusa- 


\section{Cuadro 8}

México: Características principales de la tipología de clases DE DESARROLLO

\begin{tabular}{llcc}
\hline Clase & $\begin{array}{c}\text { Nivel de } \\
\text { desarrollo }\end{array}$ & $\begin{array}{c}\text { Variación del } \\
\text { indice de de- } \\
\text { sarrollo }\end{array}$ & $\begin{array}{c}\text { Número de zonas } \\
\text { que comprende } \\
\text { cada clase }\end{array}$ \\
\hline I & Muy elevado & $157-185$ & 9 \\
II & Elevado & $121-146$ & 13 \\
III & Medio & $110-117$ & 12 \\
IV & Medio & $77-95$ & 16 \\
V & Sajo & $56-73$ & 23 \\
VI & Auy bajo & $33-50$ & 30 \\
VII & Infino & $23-29$ & 8 \\
\end{tabular}

Fuente: C. Stern, Las regiones de México y sus niveles de desarrollo socioeconómico, Tesis profesional, México, Universidad Nacional Autónoma de México, Escuela de Ciencias Políticas y Sociales, 1966. Cuadro III-1, p. 53.

rían una estructura de clases rígida. Tal rigidez disminuirá en tanto aparezcan los factores que, según el análisis realizado, son los que más influencia tienen en la modificación del sistema de estratificación. ${ }^{37}$

7. Estratificación REgIONAL, NIVEL DE URBANIZACIón Y ESTRATOS MEDios

Debido a que el presente trabajo deriva de dos investigaciones previamente realizadas, se hace necesario, dentro de un límite, integrar algunos de los resultados encontrados con anterioridad con los que son producto de este estudio.

Como se mencionó en la introducción, Stern sistematizó teórica y empíricamente el concepto de región. A base de una clasificación de 111 zonas elaborada por la Comisión Nacional de los Salarios Mínimos, ${ }^{38}$ construyó una tipología compuesta de siete clases según el nivel de desarrollo de las zonas, con base en un índice unidimensional formado por cuatro variables : población urbana, población económica-

37 En este trabajo y específicamente en esta sección, no se ha considerado un factor que tiene intima relación con las transformaciones del sistema de estratificación: la migración. Es indudable que el crecimiento de algunos estratos, especialmente los más bajos, se nutren del desplazamiento rural-urbano; si se atiende a la hipótesis de la "migración escalonada" que sugiere que la migración tiende a darse por etapas y no directamente del campo a la ciudad, es posible que las ciudades "intermedias" sean un paso transicional de los migrantes y por lo tanto nutran los rangos más bajos de la escala social. En un trabajo próximo, actualmente en elaboración, uno de los objetivos es relacionar la migración con el sistema de estratificación.

38 Comisión Nacional de los Salarios Mínimos, Memorias de los trabajos de 1963, tomos I, II, III; Descripciones geográficas económicas de las zonas; México, 1964. 
mente activa en el sector secundario, población activa en el sector terciario e ingreso por trabajador. La combinación de esas cuatro variables dio por resultado una ordenación de las 111 zonas, las que se clasificaron en función de los valores expresados a través de ese índice. El cuadro 8 resume las principales características de la tipología elaborada. Relacionando esta tipología con las 100 ciudades pequeñas y medianas analizadas en este trabajo, en función de la razón de ocupaciones no manuales a manuales, se ha encontrado que existe asociación entre ambas variables. A medida que el nivel de desarrollo zonal es mayor, la proporción de los estratos medios tiende a aumentar con. siderablemente (véase el cuadro 9). Los datos indican que el nivel de desarrollo influye notablemente en la composición del sistema de estratificación. Por lo tanto esta tipología es una variable de considerable poder explicativo, al menos en su relación con el índice de estratificación utilizado.

Ahora bien, una característica común de las siete clases obtenidas ${ }^{39}$ es que la estructura ocupacional de éstas se encuentra constituida por una mayor proporción de población activa en el sector terciario que en el secundario. Se comprueba que, en tanto disminuye el sector agrícola, aumenta el sector terciario y, a una velocidad menor, el secundario. ${ }^{40}$

Estos resultados, conjuntamente con los obtenidos en el presente trabajo, pueden llevar, bajo el supuesto de efectuarse un estudio de campo, al encuentro de algunos criterios que permitan seleccionar con algún grado de confiabilidad las ciudades donde se podría estudiar más sistemáticamente la dinámica de la clase media mercantil.

Si bien los resultados obtenidos por Stern resultan fructíferos, no lo son menos los obtenidos por Cinta, quien mediante la elaboración de un índice de urbanización, basado en trece variables y a través del método de los componentes principales, ${ }^{41}$ contribuye sustancialmente

39 En el cuadro aparecen sólo seis clases de desarrollo, ya que ninguna de las cien ciudades estudiadas corresponde a la Clase VII.

$40 \mathrm{La}$ estructura ocupacional de las siete zonas de desarrollo es la siguiente:

\begin{tabular}{cccc}
\hline & \multicolumn{3}{c}{ Sector de actividad $(\%)$} \\
\cline { 2 - 4 } Clases & Primario & Secundario & Terciario \\
\hline I & 6.2 & 39.3 & 53.1 \\
II & 38.7 & 26.3 & 33.2 \\
III & 48.6 & 19.1 & 30.9 \\
IV & 61.2 & 15.4 & 22.8 \\
V & 72.7 & 11.3 & 15.0 \\
VI & 82.4 & 7.4 & 10.1 \\
VII & 90.0 & 3.2 & 5.1 \\
\hline
\end{tabular}

Fuente: C. Stern, op. cit., pp. 59-71. Los datos son medias aritméticas. Si se observan las clases desde el nivel de desarrollo inferior al superior se percibe que el sector terciario absorbe mayor población, la que, supuestamente, se desplaza de las actividades agrícolas a las terciarias; con excepción del pasaje de la Clase III a la II, donde el sector terciario aumenta aproximadamente el $2 \%$, en contraste con el sector secundario, que gana $7 \%$.

41 Cinta, op. cit., Cap. VI. 


\section{Cuadro 9}

MéXico: Estratificación REgional Y estratos Medios

EN 100 CIUDADES PEQUEÑAS Y MEDIANAS, 1960

(En porcientos del total)

\begin{tabular}{lccc}
\hline & \multicolumn{3}{c}{ Zonas de desarrol Io } \\
\cline { 2 - 4 } & I y II II y IV V y VI \\
\hline $30 \%$ o mas de estratos medios & 70 & 36 & 13 \\
Menos de BO\% de estratos medios & 30 & 64 & 87 \\
Número de ciudades & 23 & 25 & 52 \\
\hline
\end{tabular}

a la localización de las ciudades donde pueden encontrarse estratos medios. Relacionando ahora el índice elaborado por Cinta ${ }^{42}$ con la variable estratos medios, utilizada en el actual trabajo, se encuentran los siguientes resultados que muestra el cuadro 10 . Como los estratos medios crecen paralelamente con el nivel de urbanización, es muy probable que las ciudades que presentan niveles más elevados en estas variables acusen también una estructura de clases en donde los estratos medios desempeñen un papel importante. Por lo tanto, la estratificación regional de Stern y el índice de urbanización de Cinta son elementos que permiten una aproximación más confiable en el estudio de las ciudades pequeñas y medianas. Si a esto se añaden los resultados logrados en este trabajo, será posible llegar a una etapa en la cual se pueda elaborar una estrategia confiable para la investigación del problema.

\section{Cuadro 10}

MÉXico: Nivel de uRBanización Y estratos MEDIOS EN 100 CIUDADES PEOUEÑAS Y MEDIANAS, 1960

(En porcientos del total)

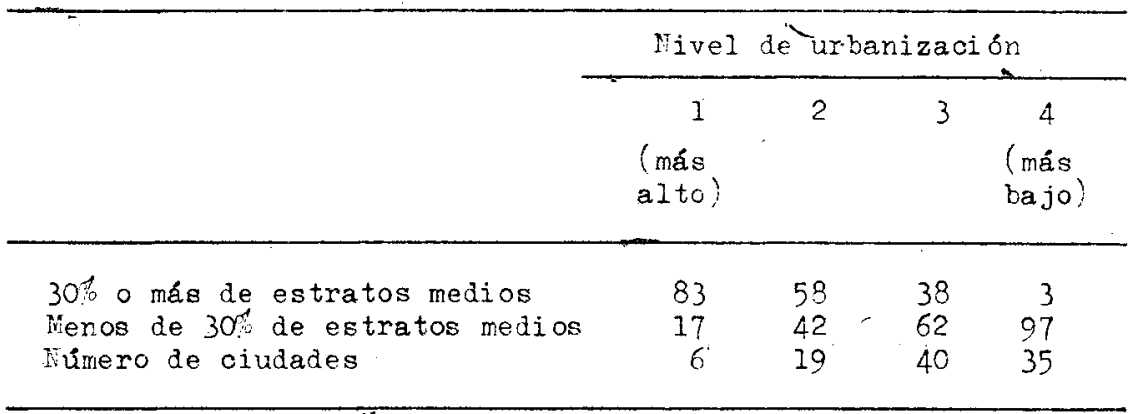

42 Los pesos que representa el nivel de urbanización fueron obtenidos con base en el valor medio del índice, la varianza, la desviación estándar y el coeficiente de variación. Ibid., p. 188. 


\section{CONSTDERACIONES FINALES}

Conforme han avanzado cada una de las sucesivas etapas de esta investigación, se ha podido comprobar la importancia del estudio de las ciudades pequeñas y medianas del país, principalmente porque, como ya se ha establecido, en ellas se está generando gran parte del desarrollo nacional. Tal como se señala en el proyecto que funda esta investigación, dichas ciudades regionales "constituyen el locus de actividades no agrícolas, pero vinculadas con el sector agrícola, muchas de las cuales representan una innovación en la estructura ocupacional regional y desempeñan un papel determinante en la dinámica del desarrollo económico".43

Conocidos algunos de los aspectos más generales de estas ciudades a partir de los estudios que anteceden a la presente, el objeto de ésta ha sido aproximarse más a la realidad de dichos centros, pero en un aspecto específico, el ya mencionado de la estratificación social. En este sentido, el presente trabajo ha permitido obtener las conclusiones que a continuación se exponen, las que, aun provisionales, pueden servir para planear una etapa posterior de la investigación.

Se obtuvo alguna evidencia que permitió probar una de las hipótesis de este trabajo: ciertamente, como se había pensado, la estructura de las ciudades pequeñas y medianas cambió al igual que la estructura global del país, aunque, como es obvio suponer, no al mismo ritmo. Evidencia en este sentido se obtuvo al encontrar que antes de 1910 la estructura de estos centros se componía de $1.5 \%$ de estratos altos (propietarios, profesionistas y técnicos) y $91.72 \%$ de estratos bajos, aproximándose así al modelo dicotómico que presentaba la estructura global del país, segúm los datos de algunos estudios citados.

Por otra parte, los datos obtenidos de 1940 y 1960 muestran cambios significativos en el sistema de estratificación: un número mayor en los estratos altos, engrosamiento de los estratos medios y descenso de la proporción de los estratos bajos. Estos cambios observados nuevamente al nivel de la estructura global se muestran en la de las ciudades estudiadas, aunque en distinta proporción, pero no por ello menos significativa.

Sin embargo, resalta el hecho particular de que estas ciudades pequeñas y medianas a diferencia de los grandes centros urbanos, de una parte, y de los centros predominantemente rurales, por la otra, presentan una estructura ocupacional predominantemente no agrícola, aun cuando asociada a este tipo de actividades. Este hecho hace suponer que atraviesan por una etapa que bien se podría denominar "transicional". Las actividades agrícolas, que son una proporción considerable del total (por aumento de la producción), y las ocupaciones urbanas que aquéllas generan a través del proceso de comercialización juegan un papel importante en los cambios que experimenta el sistema de estratificación.

Los datos relativos a la estructura ocupacional muestran tendencia a un aumento más o menos sostenido del sector terciario. Por ejem-

43 R. Stavenhagen, Proyecto de investigación sobre la burguesía rural en Méxica, El Colegio de México, 1965 (mimeografiado). 
plo, se encontró que en el período analizado la proporción de ocupados en la agricultura descendió en un $11 \%$, incrementándose el sector terciario en un $8 \%$ en tanto que el secundario en sólo $3 \%$. Con base en esta observación, se ha supuesto que el proceso de desarrollo de estos centros está en consonancia con el del país y con el que experimentan los países latinoamericanos, con tendencia al terciario recargado.

Dicho sector terciario, de acuerdo con lo que supone una de las hipótesis-guías de esta investigación (que obtuvo alguna confirmación empírica), crece en función de las actividades agrícolas, o mejor aún, en función de la comercialización del producto agrícola y de otras actividades - típicamente servicios-que se presentan a la colectividad.

Dentro de este orden de ideas, se encuentra que los estratos medios están siendo generados básicamente por el sector terciario, y sólo en mucha menor proporción por los otros sectores. Al respecto, un hecho que debe destacarse es el siguiente: si bien es cierto que a partir de la Revolución Mexicana se incrementa la proporción de estratos medios, la tendencia hacia su formación es un fenómeno anterior a ella. Así, por ejemplo, ya para 1900 se encuentra que de los ocupados en el sector terciario, el $27.5 \%$ constituía la capa de estratos medios. Esta situación, como se desprende del análisis efectuado, no es producto del movimiento revolucionario. La "terciarización" como proceso integrante del nuevo modelo de desarrollo se encontraba ya implícita antes de 1910.

El hecho anterior hace suponer que lo que la Revolución ha favorecido especialmente es una tasa alta de movilidad social que es observable precisamente por el incremento de los estratos medios. Este incremento se advierte en la actualidad no sólo en el sector terciario sino también en los dos restantes. Al respecto, se observó que el incremento porcentual de los estratos medios en el período 1900-1960 fue de $10.51 \%$.

De la tendencia observada al predominio del sector terciario es posible obtener fundamento para otra de las hipótesis-guías de esta investigación, con relación a la estructura política, o sea que "en la nueva estructura del poder que ha surgido en el campo mexicano a raíz de la reforma agraria, los grupos sociales asociados a las actividades terciarias tienden a jugar un papel predominante". ${ }^{44}$

Señaladas en términos generales algunas de las observaciones que se pueden deducir del presente trabajo, resta esperar que una etapa posterior de investigación de campo permita verificar las hipótesis que orientan esta investigación, así como las que se han desprendido de cada una de sus etapas. 


\section{APÉNDICE METODOLÓGICO}

A fin de lograr un mínimo de comparabilidad entre 1900, 1940 y 1960 , se adoptó como criterio ordenador de los datos la clasificación ocupacional que aparece en el VIII Censo General de Población de 1960 (véase antes el cuadro 2 ). Se pensó que esta clasificación permitiría observar algunos de los cambios cuantitativos, aun cuando no los cualitativos, más importantes en la estructura de clases en el período señalado. Concretamente, la clasificación elaborada debería cumplir al menos con los siguientes requisitos: a) ser una medida, aun mínima, de comparabilidad entre los años seleccionados con objeto de b) dar una imagen aproximada de la dinámica y las características de la estratificación ocupacional.

Uno de los principales problemas que hubo que afrontar en el desarrollo de este procedimiento fue el de las diferencias conceptuales en cada uno de los censos. El censo de 1900 presenta los datos según la ocupación principal en función de la actividad económica. Estos datos se encuentran ampliamente desglosados; por ejemplo, la rama de "bellas artes, industrias y oficios" especifica 89 ocupaciones. Aunque éste fue un factor que contribuyó en buena medida a reclasificar las ocupaciones en función de las categorías del censo de 1960, la falta de definiciones precisas de las ocupaciones dificultó la clasificación de algunas de ellas. Por otra parte, fue necesario introducir algunas modificaciones adicionales, entre las que destacan aquellas ocupaciones que estando antes clasificadas en la rama de actividad "industrial" (compuesta principalmente por artesanías) pasaron a formar parte de las categorías "agricultura" o "servicios personales", establecida, esta última, en el censo de 1960.

El censo de 1940 presenta los datos conforme al criterio de la posición en la ocupación según rama de actividad económica, y da al respecto sólo seis categorías ocupacionales: a) propietarios, socios $\mathrm{y}$ empresarios; $b$ ) empleados y dependientes; $c$ ) obreros y jornaleros; d) ayudan a la familia sin retribución; e) propietarios de empresa no directores e individuos que trabajan solos, y f) profesionistas. Las dificultades encontradas en este censo fueron mayores que en el de 1900, pues la información viene sumamente agregada y las posiciones ocupacionales mencionadas son distintas a las que emplea el censo de 1960 . Sin embargo, con ayuda de las divisiones por rama de actividad, fue posible mantener los requisitos para fundamentar la clasificación. Así, por ejemplo, los obreros y jornaleros del sector secundario fueron clasificados en la categoría de "obreros ocupados en el proceso de producción de bienes y servicios", señalada en el censo de 1960.

No obstante, conviene aclarar dos problemas principales: el primero de ellos se presentó con respecto al grupo de "vendedores" o "comerciantes"; la quinta división del censo de 1940, denominada "comercio", no especifica con claridad quiénes constituyen este grupo. La solución alternativa fue tomar los grupos de "individuos que trabajan solos" y "propietarios de empresa, directores e individuos que trabajan solos", englobados bajo la rama de actividad "comercio", 
como el estrato correspondiente a los "vendedores" que aparecen en el año de 1960. El segundo problema surgió con respecto a la categoría "trabajan por su cuenta". Éstos fueron clasificados en la categoría de "servicios personales", excepto los que se encontraban dentro de la rama de actividad "comercio". Esta decisión tiene su fundamento en lo que se especifica en la Nomenclatura nacional de ocupaciones de 1940 que establece que este grupo corresponde precisamente al de comerciantes en general. ${ }^{1}$

En el censo de 1960, se dispone de la información tanto de la posición en la ocupación como de la ocupación principal según la rama de actividad. Se podría pensar que los problemas serían mínimos; sin embargo, los datos se encuentran sumamente agregados y en consecuencia la clasificación elaborada ha adolecido de esa limitación. ${ }^{2}$

Las clasificaciones ocupacionales correspondientes a los años de 1900 y 1940, aun cuando tienen las mismas categorías del año de 1960, deben ser calificadas como provisionales y tentativas pues, como se anotó, las diferencias conceptuales experimentan muchas variaciones entre un censo y otro.

La categoría "obreros y jornaleros ocupados en el proceso de producción de bienes y servicios" correspondiente al censo de 1960 viene subdividida en dos clases: los relacionados directa y los indirectamente con el proceso. En este trabajo, la subdivisión no fue considerada y se tomó la categoría en su conjunto.

1 Secretaría de la Economía Nacional, Nomenclatura nacional de ocupaciones, México, Dirección General de Estadística, 1941.

2 R. Stavenhagen, en un proyecto de estudio en El Colegio de México sobre una muestra del $1.5 \%$ del censo de 1960, propone una clasificación ocupacional de 41 categorías, lo que demuestra que la clasificación elaborada en el censo es muy agregada. 